\title{
Evaluation of the Farmers' Markets for Kids programme
}

\author{
Rachel Dannefer*, Erica Bryan, Alyce Osborne and Rachel Sacks \\ New York City Department of Health and Mental Hygiene, Bureau of Chronic Disease Prevention and Tobacco \\ Control, 42-09 28th Street, 11 th Floor - CN 153, Long Island City, NY 11101 , USA
}

Submitted 9 0ctober 2015: Final revision received 14 April 2016: Accepted 13 May 2016: First published online 28 July 2016

\begin{abstract}
Objective: To assess the impact of Farmers' Markets for Kids, a farmers' marketbased, child-oriented nutrition education programme, on attitudes and behaviours related to preparing and consuming produce among child participants and their caregivers in New York City (NYC).

Design: Retrospective pre-test/post-test cross-sectional survey with caregivers of children participating in Farmers' Markets for Kids classes.

Setting: Four NYC farmers' markets where Farmers' Markets for Kids classes are implemented; these markets serve low-income communities.

Subjects: Two hundred and twelve adult caregivers of children who participated in Farmers' Markets for Kids classes.

Results: Caregivers reported that children's consumption of fruits and vegetables had increased since participating in Farmers' Markets for Kids and that their children more frequently assisted with food preparation; both of these improvements were statistically significant. Caregivers also reported significant improvements in attitudes: since participating in Farmers' Markets for Kids, their children were more willing to try new fruits and vegetables and caregivers found it easier to prepare fruits and vegetables for their children. Almost all respondents (99\%) reported purchasing more fruits and vegetables since participating in Farmers' Markets for Kids and 95\% had prepared the programme's recipes at home.

Conclusions: Findings suggest that Farmers' Markets for Kids may be an effective approach for increasing produce consumption among participating children and improving related attitudes among children and caregivers. This evaluation provides support for future efforts to undertake more rigorous evaluations of such programmes.
\end{abstract}

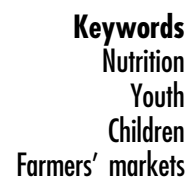

A diet rich in fruits and vegetables is associated with a decreased risk of chronic diseases such as heart disease, stroke, diabetes and some cancers ${ }^{(1)}$. Ensuring sufficient consumption of fruits and vegetables among children is especially critical, as eating habits and food preferences established in childhood influence lifelong dietary behaviours $^{(2)}$. Yet most children consume far fewer than the recommended servings of fruits and vegetables daily and children of lower socio-economic status consume even less produce than those of higher socio-economic status $^{(3,4)}$. In New York City (NYC), only $16 \%$ of children aged 6-12 years consume the recommended five or more servings of fruits and vegetables daily and children in lower-income households consume significantly fewer servings than those in higher-income households ( 2.8 servings/d for children in households below $200 \%$ of the Federal Poverty Level $v .3 .2$ servings/d for those in households at or above $400 \%$ of the Federal Poverty Level, $P=0.03$ ). Hispanic children also consume significantly fewer servings of fruits and vegetables than non-Hispanic children $(2.5 v .3 .1 \text { servings/d, } P<0 \cdot 001)^{(5)}$. The low rates of fruit and vegetable consumption and associated disparities indicate a need for concentrated resources to improve diets among children, particularly those from lower-income families.

Farmers' markets have been identified as a promising avenue for promoting fruit and vegetable consumption $^{(6-8)}$. One study found that introducing small farmers' markets in low-income communities with limited fruit and vegetable availability increased produce consumption among neighbourhood residents ${ }^{(9)}$. Interventions tying health promotion activities to farmers' markets, such as fruit and vegetable voucher programmes and nutrition classes, have shown improvements in attitudes and behaviours related to produce consumption ${ }^{(10-12)}$. Building on this evidence, in 2013, the NYC Department of Health and Mental Hygiene (Health Department) launched Farmers' Markets for Kids to increase produce 
consumption among children, as one component of the Health Department's socioecological approach to improving access to and availability of fruits and vegetables for all New Yorkers ${ }^{(13)}$. Farmers' Markets for Kids (formerly known as Come See What's Cooking, Kids!) operates at farmers' markets serving low-income communities and combines bilingual nutrition education for children and their caregivers with vouchers for fresh produce. The programme is supported by funding from the Doris Duke Charitable Foundation.

In 2014, the Health Department administered retrospective pre-test/post-test surveys to caregivers of children participating in Farmers' Markets for Kids in order to assess the programme's impact on attitudes and behaviours towards produce preparation and consumption among child participants and their caregivers. To our knowledge, the current paper is the first presenting the results of an evaluation of a farmers' market-based, child-oriented nutrition education programme.

\section{Methods}

\section{Intervention}

Farmers' Markets for Kids aims to motivate children to eat more fresh fruits and vegetables in order to prevent diet-related chronic disease. The programme was developed and piloted in 2013 to leverage the success of Stellar Farmers' Markets, an adult-oriented Supplemental Nutrition Assistance Program Nutrition Education (SNAPEd) initiative, which has been associated with significant increases in produce consumption among adult participants $^{(12)}$. Stellar Farmers' Markets aims to improve dietary habits by providing education and resources for planning, purchasing and preparing healthy meals that include locally grown produce. Since its launch in 2009, Stellar Farmers' Markets has reached more than 119866 non-unique contacts in primarily low-income neighbourhoods and has provided more than \$US 179000 for fresh produce in the form of \$US 2 Health Bucks coupons. These \$US 2 coupons are offered through the Health Department and may be redeemed for fresh fruits and vegetables at any farmers' market in NYC. In addition to serving as an incentive for participation in health-related activities, customers receive one Health Buck coupon for every \$US 5 they spend using electronic benefit transfer (EBT) at markets that accept EBT/SNAP benefits.

Farmers' Markets for Kids creates a designated space at the farmers' market for children to engage in fun, hands-on activities designed to increase their familiarity with and consumption of local fruits and vegetables. The programme operates at four farmers' markets in NYC where Stellar Farmers' Market classes also take place: the 125th Street Fresh Connect Farmers' Market in Central Harlem; the EcoStation:NY Bushwick Farmers' Market in
Brooklyn; and the Corona and Jackson Heights Greenmarkets in Queens. With the exception of Jackson Heights, the markets are located in high-poverty neighbourhoods where at least $20 \%$ of residents live below the Federal Poverty Level threshold. The Jackson Heights market is located in a medium-poverty neighbourhood (10 to $<20 \%$ of residents below the Federal Poverty Level $)^{(14,15)}$ and this market has high EBT sales in relation to other markets, indicating substantial patronage by lower-income clientele. A large proportion of residents in the areas surrounding each of the markets featuring Farmers' Markets for Kids is Latino/Hispanic (Bushwick, $80 \%$; Corona, $74 \%$; Jackson Heights, $57 \%$; Harlem, 26\%), and in 2014 the majority of attendees were Latino $(71 \%$ of caregivers, $66 \%$ of children). Workshops are made relevant and accessible for Latino audiences through provision of bilingual handouts, interpretation at each workshop and recipes which use ingredients familiar to these audiences. All of these markets operate weekly and Farmers' Markets for Kids offers workshops at the markets each week from July through early November. Workshops are free and open to the public, and do not require pre-registration.

The Farmers' Markets for Kids curriculum contains six lessons on topics such as smart snacking, eating a variety of colourful fruits and vegetables and exploring the path food takes from farm to market. Each lesson includes activities for children and messaging directed at caregivers to promote healthy eating at home. Handouts and recipes are distributed to caregivers to reinforce key messages (Table 1). The curriculum was adapted from Eat Well Play Hard in Child Care Settings, an evidence-based nutrition education programme for children of pre-school age developed by the New York State Department of Health ${ }^{(16)}$.

Farmers' Markets for Kids workshops last approximately $20 \mathrm{~min}$ and are repeated up to four times per market day. Workshops are conducted under a farmers' market tent by a three-person team consisting of a nutritionist, a culinary educator and a bilingual educator. The nutritionist leads an interactive, sensory-based lesson (Table 1) followed by a guided tasting of a recipe highlighting a seasonal fruit or vegetable, led by the culinary educator; the bilingual educator provides English-Spanish interpretation during the workshop. Recipe ingredients are passed around for children to touch, smell and see, and adult caregivers learn about how to reinforce healthy eating at home. All participants have an opportunity to taste a recipe. Caregivers are invited to complete a survey which captures basic demographic information about themselves and their children. For completing the survey, each participating child (aged 3 to 11 years) and one caregiver per family receive a \$US 2 Health Bucks coupon. In 2014, Farmers' Markets for Kids staff led 202 workshops with an average of forty-seven children and caregivers per class. The programme had 9472 non-unique participants 
Table 1 Farmers' Markets for Kids curriculum overview, 2014

Lesson 1. Vary Your Veggies

Objectives:

- Name three colourful vegetables

- Say why they should eat a variety of vegetables every day

- Name one new vegetable they are willing to try

Activities: Eat A Rainbow, Touch Taste Smell and See

Lesson 2. Flavourful Fruit

Objectives:

- Name three colourful fruits

- Say why they should eat fruits every day

- Name one new fruit they are willing to try

Activities: Fruit Mystery Bag, Fruit Tasting

Lesson 3. Smart Snacking

Objectives:

- State one reason why it is important to eat healthy snacks

- Name one new healthy snack that they will try

Activities: Blastoff, Build a Healthy Snack

Lesson 4. Growing Goodness

Objectives:

- Explain that farmers grow fruits and vegetables

- Identify that there are different parts of the plant

- Know that fruits and vegetables start from seeds

Activities: Start with a Seed, Parts of the Plant

Lesson 5. Terrific Tastes

Objectives:

- Name four tastes: sour, bitter, sweet, salty

- Be able to describe one fruit/vegetable they like

- Name one new fruit or vegetable they are willing to try

Activities: Taste Adventure, Super Smellers

Lesson 6. Follow Your Food

Objectives:

- Understand why farmers and farms are important

- Be able to describe how a farmer gets his/her fruits and vegetables from the farm to the farmers' market

Activities: Farm to Farmers' Market, Meet Your Farmer

(6159 children and 3313 adults), representing more than 1500 unique families. Recipients received more than \$US 20000 worth of Health Bucks, of which $88 \%$ were redeemed.

\section{Evaluation design}

The Health Department surveyed caregivers of children participating in Farmers' Markets for Kids using a retrospective pre-test/post-test design. Questions that addressed nutrition-related behaviours and attitudes before participating in Farmers' Markets for Kids classes were paired with questions about current attitudes and behaviours. This design was chosen because it was anticipated that a traditional pre/post evaluation would yield very low response rates for post-surveys, since Farmers' Markets for Kids is a drop-in programme with no registration. The retrospective pre-test/post-test design allows all data to be collected at one time point and is therefore useful when it is not feasible to track participants over time ${ }^{(17)}$.
Additionally, this approach has been used for other nutrition education evaluations ${ }^{(18,19)}$ and some researchers have proposed that this design may help to address response-shift bias for self-reported measures, which are frequently used in evaluations of nutrition-related evaluations $^{(20)}$.

This evaluation design was reviewed by the Health Department Institutional Review Board, which determined that the project did not fall under the purview of the Board as it constituted a public health programme evaluation that is non-research.

\section{Data collection}

Surveys were conducted at all four markets featuring Farmers' Markets for Kids over a one-week period in August 2014. Surveys were available in English and Spanish, and were distributed to caregivers directly following each workshop. Respondents were required to be at least 18 years old and received a \$US 2 Health Bucks coupon as an incentive for completing the survey. This Health Bucks coupon was provided in addition to the standard Farmers' Markets for Kids' incentive for participating in the workshop. Health Department staff were available during data collection to assist respondents if needed. The survey was completed by 279 respondents; however, for the analyses reported in the current paper, sixty-seven respondents whose children attended their first Farmers' Markets for Kids class on the day of the survey were excluded. These respondents were removed from analyses because children attending their first class on the day of the survey did not have the opportunity to implement changes between completing the class and taking the survey; thus, changes in attitudes and behaviours among those children could not be captured. The final sample for the present analyses was comprised of the 212 caregivers of children who had attended at least two Farmers' Markets for Kids classes.

\section{Survey development and measures}

Survey questions were adapted from a number of sources as cited below. Because caregivers may have had more than one child at the Farmers' Markets for Kids workshop, they were instructed to respond to survey questions while thinking about their oldest child who had attended the class on that day. The survey was pre-tested in English and Spanish with fifteen programme participants at multiple markets to ensure comprehension of the instructions and questions, determine an acceptable length for the survey, and establish the clearest format and language for the retrospective pre-test/post-test questions. For these questions, respondents were asked about behaviours and attitudes before taking kids' classes and now.

\section{Child behaviour: produce consumption and food} preparation

Retrospective pre-test/post-test measures assessed the child's produce consumption and participation in food 
preparation before and after taking Farmers' Markets for Kids classes. Questions on produce consumption were modified from the University of California Cooperative Extension Food Behavior Checklist, a validated tool to assess fruit and vegetable consumption among audiences with limited resources ${ }^{(21)}$. To assess the quantity of fruits and vegetables consumed by each child, the survey listed examples of quantities of fruits and vegetables that constitute one cup (i.e. 2 large plums, 1 ear of corn), followed by separate open-ended questions about how many cups of fruit and how many cups of vegetables the child usually consumed on days when s/he was with the caregiver (i.e. the survey respondent) for the entire day. The specification of the 'entire day' was included because caregivers might not be able to accurately estimate their child's consumption on days that they were not with their child all day. Responses to these questions were summed to create a measure of total cups of fruits and vegetables consumed by the child daily.

To assess consumption of a variety of produce, caregivers were asked how often the child ate more than one kind fruit when $\mathrm{s} /$ he was with the caregiver for the entire day, with a parallel question for vegetables. These questions were modified from the Food Behavior Checklist ${ }^{(21)}$. An additional question that asked how often the child helped prepare a meal or snack was modified from a survey developed and implemented as part of the Eat Well Play Hard in Child Care Settings programme ${ }^{(22)}$. Response options for these questions ranged from 'never' to 'always', on a 5 -point scale ( $1=$ 'never', $5=$ 'always').

\section{Attitudes towards produce consumption and preparation Retrospective pre-test/post-test questions addressed attitudinal measures for caregivers as well as children. Caregivers were asked how easy it is to prepare fruits and to prepare vegetables that the child will eat (original questions, 4-point scale, $1=$ 'not easy' to $4=$ 'very easy'). These two measures were averaged to create a scale representing caregivers' attitudes on the ease of preparing fruits and vegetables for the child (Cronbach's $\alpha=0.78$ ). Caregivers were also asked how willing the child was to try new fruits, with a separate question on vegetables (4-point scale, $1=$ 'not at all willing' to $4=$ 'very will- ing' $)^{(12)}$. Again, these two items were averaged to create a scale (Cronbach's $\alpha=0.77$ ). Values for both scales ranged from 1 to 4 , with higher values representing more positive attitudes.}

\section{Programme participation, shopping behaviour and Health Bucks}

Caregivers were asked how many Farmers' Markets for Kids classes the child had attended that year. Responses ranged from ' 1 ' to ' 6 or more'. Caregivers were also asked whether they had purchased more fruits and vegetables since attending Farmers' Markets for Kids classes, prepared any of the recipes at home and participated in the adult-oriented Stellar Farmers' Markets programme (responses: 'yes', 'no', 'unsure').

Questions related to Health Bucks included how often the child used the Health Bucks coupon from the class to buy the fruit or vegetable featured in the class that day (5-point scale from $1=$ 'never' to $5=$ 'always') and how likely the caregiver would be to attend Farmers' Markets for Kids without the Health Bucks incentive (4-point scale, $1=$ 'very unlikely' to $4=$ 'very likely').

\section{Demographics}

Demographic questions covered child and caregiver age, gender and race/ethnicity, the caregiver's education level and relationship to the child who was the subject of the survey, and household participation in EBT, the Special Supplemental Nutrition Program for Women, Infants, and Children (WIC) and other food assistance programmes during the past 12 months.

\section{Analysis}

Bivariate analyses were conducted using $\chi^{2}$ and paired $t$ tests to compare outcomes of interest before and after participation in Farmers' Markets for Kids, including child produce consumption, involvement in food preparation and attitudes towards trying new fruits and vegetables, and caregiver attitudes about ease for preparing fruits and vegetables for their children. Linear regression analyses using mixed models were conducted to compare estimates for these outcomes before and after participation in Farmers' Markets for Kids while controlling for covariates, including child gender and age, and caregiver gender, age and education level, participation in Stellar Farmers' Markets and the market where the survey was completed. The number of Farmers' Markets for Kids classes attended by the child that summer was also included in the regression models to test for a dose-response relationship between positive outcomes and class attendance. Race/ ethnicity was not included as there was little variation in this area (more than $90 \%$ of the sample was Hispanic). Sensitivity analyses were performed to compare outcomes for caregivers who had participated in a Stellar Farmers' Market class with those who had not, since participation in this programme could have modified the impact of Farmers' Markets for Kids. For these analyses, $t$ tests were used to compare mean improvements in outcomes among respondents based on whether or not they had participated Stellar Farmers' Markets. Finally, a sensitivity analysis was conducted to compare respondents who were likely $v$. those who were not likely to attend the class without the Health Bucks coupon in order to explore whether the programme affected these groups differently, also using $t$ tests to compare improvements between these groups. Analyses were performed in the statistical software package SAS version 9.2 with $\alpha=0.05$. 


\section{Results}

\section{Sample}

The 212 caregivers included in the study sample had an average of two children attending the Farmers' Markets for Kids class on the day of the survey. For the child who was the focus of the survey (i.e. the respondent's oldest child attending class that day), ages ranged from 2 to 15 years, with a median of 7 years. Most of the children were Hispanic/Latino (93\%) and 58\% were girls (Table 2). Children had attended a median of three Farmers' Markets for Kids classes since 1 July 2014, at the farmers' market where they were surveyed.

The majority of respondents (94\%) were parents of the children attending Farmers' Markets for Kids, female (91\%) and Hispanic/Latino (92\%). Fifty-nine per cent were between 30 and 39 years of age. Education among respondents was low, with $62 \%$ reporting an 8 th grade education or less. Ninety-two per cent had participated in at least one food assistance programme in the past year, most commonly EBT (65\%) and WIC (54\%; Table 2). Most of the surveys were completed in Spanish (91\%).

The Corona farmers' market had the highest number of completed surveys ( $n$ 140) followed by Bushwick ( $n$ 40), Jackson Heights ( $n$ 30) and 125th Street ( $n$ 2). This distribution reflects programme participation at each site throughout the season (Table 3 ). In the case of the 125 th Street market, the low number of surveys reflected the fact the majority of children at that site attended as part of their participation in summer camps, pre-schools and other educational programmes, rather than coming with individual parents or caregivers. This difference translated to fewer eligible caregivers completing the survey in the Harlem market than in the other three markets surveyed.

\section{Behaviours and attitudes: retrospective pre-test/ post-test questions}

Caregivers reported that since participating in Farmers' Markets for Kids, their children's fruit consumption increased from a mean of 1.4 to $2.3 \mathrm{cups} / \mathrm{d}$ and vegetable consumption increased from a mean of $1 \cdot 2$ to $2 \cdot 1$ cups/d (all $P<0.0001$ ), yielding a combined mean increase in produce consumption from $2 \cdot 6$ to 4.3 cups daily $(P<0.0001)$. Caregivers reported an increase in the variety of produce their children consumed since participating in Farmers' Markets for Kids. The percentage reporting that their children usually or always ate more than one kind of fruit and more than one kind of vegetable daily increased significantly after the children participated in the programme (fruit, $46 \%$ to $86 \%$; vegetables, $36 \%$ to $78 \%$; all $P<0.0001)$. Child involvement in food preparation also increased, with $61 \%$ of caregivers reporting their children usually or always helped them prepare meals or snacks, compared with $32 \%$ before participation in Farmers' Markets for Kids $(P<0 \cdot 0001)$.
Table 2 Characteristics of Farmers' Markets for Kids survey respondents and their children, New York City, 2014 ( $n$ 212)

\begin{tabular}{|c|c|c|c|}
\hline & $n$ & $\%$ & $95 \% \mathrm{Cl}$ \\
\hline \multicolumn{4}{|l|}{ Child age (years) } \\
\hline $2-4$ & 37 & 17.5 & $12 \cdot 4,22 \cdot 7$ \\
\hline $5-8$ & 106 & 50.2 & $43 \cdot 4,57 \cdot 0$ \\
\hline $9-11$ & 61 & 28.9 & $22 \cdot 7,35 \cdot 1$ \\
\hline $12-15$ & 7 & 3.3 & $0.9,5.8$ \\
\hline \multicolumn{4}{|l|}{ Child gender } \\
\hline Female & 122 & 57.5 & $50 \cdot 8,64 \cdot 3$ \\
\hline \multicolumn{4}{|l|}{ Child race } \\
\hline White & 2 & 0.9 & $0.0,2 \cdot 3$ \\
\hline African American & 1 & 0.5 & $0.0,1.4$ \\
\hline Hispanic & 198 & 93.4 & $90 \cdot 0,96 \cdot 8$ \\
\hline Other & 11 & $5 \cdot 2$ & $2 \cdot 2,8 \cdot 2$ \\
\hline \multicolumn{4}{|c|}{ Number of Farmers' Markets for Kids classes attended by child } \\
\hline 1 & 15 & $7 \cdot 2$ & $3 \cdot 7,10 \cdot 8$ \\
\hline 2 & 46 & 22.2 & $16 \cdot 5,27 \cdot 9$ \\
\hline 3 & 45 & 21.7 & $16 \cdot 1,27 \cdot 4$ \\
\hline 4 & 44 & 21.3 & $15 \cdot 6,26 \cdot 9$ \\
\hline 5 & 28 & 13.5 & $8.8,18.2$ \\
\hline 6 or more & 29 & $14 \cdot 0$ & $9 \cdot 2,18 \cdot 8$ \\
\hline \multicolumn{4}{|l|}{ Caregiver relationship to child } \\
\hline Parent & 199 & 93.9 & $90 \cdot 6,97 \cdot 1$ \\
\hline Other relative & 13 & $6 \cdot 1$ & $2 \cdot 9,9.4$ \\
\hline \multicolumn{4}{|l|}{ Caregiver age (years) } \\
\hline $19-29$ & 42 & $20 \cdot 3$ & $14 \cdot 8,25 \cdot 8$ \\
\hline $30-39$ & 123 & 59.4 & $52 \cdot 7,66 \cdot 2$ \\
\hline $40-49$ & 36 & $17 \cdot 4$ & $12 \cdot 2,22 \cdot 6$ \\
\hline $50+$ & 6 & 2.9 & $0.6,5.2$ \\
\hline \multicolumn{4}{|l|}{ Caregiver gender } \\
\hline Female & 191 & 91.4 & $87 \cdot 6,95 \cdot 2$ \\
\hline \multicolumn{4}{|l|}{ Caregiver race/ethnicity } \\
\hline White & 1 & 0.5 & $0.0,1.4$ \\
\hline African American & 1 & 0.5 & $0.0,1.4$ \\
\hline Hispanic & 195 & 92.0 & $88.3,95 \cdot 7$ \\
\hline Other & 15 & $7 \cdot 1$ & $3.6,10.6$ \\
\hline \multicolumn{4}{|l|}{ Caregiver education } \\
\hline 8 th grade or less & 129 & $62 \cdot 3$ & $55 \cdot 7,69 \cdot 0$ \\
\hline 9 th to 11 th grade & 28 & 13.5 & $8.8,18.2$ \\
\hline 12th grade or GED & 37 & 17.9 & $12 \cdot 6,23 \cdot 1$ \\
\hline Any college or higher & 13 & $6 \cdot 3$ & $2 \cdot 9,9.6$ \\
\hline \multicolumn{4}{|c|}{ Caregiver participation in Stellar Farmers' Markets programme } \\
\hline Yes & 177 & 84.7 & $79.8,89.6$ \\
\hline No & 32 & $15 \cdot 3$ & $10 \cdot 4,20 \cdot 2$ \\
\hline \multicolumn{4}{|c|}{$\begin{array}{l}\text { Household food assistance programme participation in past } \\
12 \text { months }\end{array}$} \\
\hline Any programme & 194 & $92 \cdot 4$ & $88 \cdot 8,96 \cdot 0$ \\
\hline EBT/SNAP & 137 & $65 \cdot 2$ & $58 \cdot 7,71 \cdot 7$ \\
\hline WIC & 114 & $54 \cdot 3$ & $47 \cdot 5,61 \cdot 1$ \\
\hline Free school or summer meals & 87 & 41.4 & $34.7,48 \cdot 1$ \\
\hline Food pantry & 3 & 1.4 & $0.0,3.0$ \\
\hline
\end{tabular}

GED, General Educational Development; EBT, electronic benefit transfer; SNAP, Supplemental Nutrition Assistance Program; WIC, Special Supplemental Nutrition Program for Women, Infants, and Children.

Caregivers reported increases in children's willingness to try new fruits and vegetables. While $58 \%$ said their child was very willing or willing to try new fruits and $44 \%$ said their child was very willing or willing to try new vegetables before the classes, these percentages increased to $90 \%$ for fruits and $87 \%$ for vegetables following the classes (all $P<0.0001)$. Scale values for willingness to try new fruits and vegetables increased from $2 \cdot 5$ to 3.3 $(P<0.0001)$. Ease of preparing fruits and vegetables for children increased, with most respondents reporting that it 
Table 3 Number of survey respondents and programme participants by market, New York City, 2014

\begin{tabular}{|c|c|c|c|c|c|c|c|}
\hline & \multirow{2}{*}{\multicolumn{3}{|c|}{ Survey respondents $(n 212)$}} & \multicolumn{4}{|c|}{ Participation in Farmers' Markets for Kids Classes during the 2014 season } \\
\hline & & & & \multicolumn{2}{|c|}{ Caregivers } & \multicolumn{2}{|c|}{ Child participants } \\
\hline & $n$ & $\%$ & $95 \% \mathrm{Cl}$ & Total number & Mean per class & Total number & Mean per class \\
\hline 125th Street, Manhattan & 2 & 0.9 & $0.0,2 \cdot 3$ & 216 & 6 & 545 & 14 \\
\hline Bushwick, Brooklyn & 40 & 18.9 & $13 \cdot 6,24 \cdot 2$ & 681 & 14 & 1185 & 24 \\
\hline Corona, Queens & 140 & $66 \cdot 0$ & $59 \cdot 6,72 \cdot 5$ & 1697 & 29 & 3145 & 54 \\
\hline Jackson Heights, Queens & 30 & $14 \cdot 2$ & $9.4,18.9$ & 719 & 13 & 1284 & 23 \\
\hline
\end{tabular}

Table 4 Multivariable linear regression models for behaviours and attitudes related to produce consumption and food preparation for the Farmers' Markets for Kids programme evaluation, New York City, 2014 ( $(n 212)$

\begin{tabular}{|c|c|c|c|c|c|c|c|c|c|c|c|c|}
\hline & \multicolumn{2}{|c|}{$\begin{array}{l}\text { Total cups of } \\
\text { F\&V consumed } \\
\text { daily }\end{array}$} & \multicolumn{2}{|c|}{$\begin{array}{l}\text { Frequency of } \\
\text { child eating } \\
\text { more than one } \\
\text { kind of fruit daily }\end{array}$} & \multicolumn{2}{|c|}{$\begin{array}{l}\text { Frequency of } \\
\text { child eating } \\
\text { more than one } \\
\text { kind of } \\
\text { vegetable daily }\end{array}$} & \multicolumn{2}{|c|}{$\begin{array}{l}\text { Frequency of } \\
\text { child helping to } \\
\text { prepare meals } \\
\text { and snacks }\end{array}$} & \multicolumn{2}{|c|}{$\begin{array}{l}\text { Ease of } \\
\text { preparing F\&V } \\
\text { child will eat }\end{array}$} & \multicolumn{2}{|c|}{$\begin{array}{l}\text { How willing the } \\
\text { child is to try } \\
\text { new F\&V }\end{array}$} \\
\hline & $\beta$ & SE & $\beta$ & SE & $\beta$ & $\mathrm{SE}$ & $\beta$ & SE & $\beta$ & SE & $\beta$ & SE \\
\hline \multicolumn{13}{|c|}{ Farmers' Markets for Kids participation } \\
\hline Before participating & \multicolumn{2}{|c|}{ Ref. } & \multicolumn{2}{|c|}{ Ref. } & \multicolumn{2}{|c|}{ Ref. } & \multicolumn{2}{|c|}{ Ref. } & \multicolumn{2}{|c|}{ Ref. } & \multicolumn{2}{|l|}{ Ref. } \\
\hline After participating & $1.806^{\star \star \star}$ & 0.113 & $0.922^{\star \star}$ & 0.080 & $0.958^{\star \star \star}$ & 0.073 & $0.853^{\star \star}$ & 0.073 & $0.764^{\star \star}$ & 0.056 & $0.741^{\star \star \star}$ & 0.055 \\
\hline $\begin{array}{l}\text { Number of Farmers' Markets } \\
\text { for Kids classes } \\
\text { attended }\end{array}$ & 0.007 & 0.092 & -0.053 & 0.044 & -0.016 & 0.049 & 0.035 & 0.051 & -0.003 & 0.034 & -0.005 & 0.033 \\
\hline \multicolumn{13}{|l|}{ Market } \\
\hline Corona & \multicolumn{2}{|c|}{ Ref. } & \multicolumn{2}{|c|}{ Ref. } & \multicolumn{2}{|c|}{ Ref. } & \multicolumn{2}{|c|}{ Ref. } & \multicolumn{2}{|c|}{ Ref. } & \multicolumn{2}{|l|}{ Ref. } \\
\hline Jackson Heights & 0.421 & 0.434 & -0.181 & 0.206 & -0.174 & 0.227 & 0.137 & 0.236 & -0.010 & 0.160 & -0.067 & 0.153 \\
\hline Bushwick & -0.025 & 0.342 & 0.041 & 0.166 & -0.107 & 0.182 & -0.016 & 0.190 & -0.067 & 0.128 & -0.042 & 0.123 \\
\hline 125th Street & $2 \cdot 297$ & 1.315 & -0.835 & 0.636 & -0.120 & 0.700 & 1.397 & 0.730 & 0.260 & 0.493 & -0.118 & 0.472 \\
\hline Child age & 0.019 & 0.051 & -0.016 & 0.025 & 0.027 & 0.027 & $0.064^{*}$ & 0.028 & 0.003 & 0.019 & 0.012 & 0.018 \\
\hline \multicolumn{13}{|l|}{ Child gender } \\
\hline Male & \multicolumn{2}{|c|}{ Ref. } & \multicolumn{2}{|c|}{ Ref. } & \multicolumn{2}{|c|}{ Ref. } & \multicolumn{2}{|c|}{ Ref. } & \multicolumn{2}{|c|}{ Ref. } & \multicolumn{2}{|c|}{ Ref. } \\
\hline Female & -0.077 & 0.264 & 0.077 & 0.128 & 0.190 & 0.140 & 0.202 & 0.146 & 0.054 & 0.099 & $0.292^{\star *}$ & 0.095 \\
\hline Caregiver age & 0.026 & 0.020 & 0.005 & 0.010 & 0.017 & 0.011 & 0.009 & 0.011 & 0.005 & 0.008 & 0.004 & 0.007 \\
\hline \multicolumn{13}{|l|}{ Caregiver gender } \\
\hline Male & \multicolumn{2}{|c|}{ Ref. } & $\mathrm{Re}$ & & $\operatorname{Re}$ & & $\operatorname{Re}$ & & $\operatorname{Re}$ & & Ref. & \\
\hline Female & 0.608 & 0.524 & 0.006 & 0.253 & -0.085 & 0.278 & -0.077 & 0.290 & 0.034 & 0.196 & -0.181 & $0 \cdot 188$ \\
\hline Caregiver education & & & & & & & & & & & & \\
\hline 8th grade or less & $\mathrm{Re}$ & & $\mathrm{Re}$ & & $\mathrm{Re}$ & & $\mathrm{Re}$ & & $\mathrm{Re}$ & & Ref & \\
\hline 9 th to 11 th grade & 0.084 & 0.405 & 0.053 & 0.193 & 0.033 & 0.212 & -0.078 & 0.222 & 0.196 & 0.150 & 0.020 & 0.143 \\
\hline 12th grade/GED & -0.183 & 0.360 & -0.047 & 0.174 & -0.242 & 0.191 & -0.216 & 0.200 & -0.161 & 0.135 & -0.122 & 0.129 \\
\hline Any college or higher & -0.276 & 0.615 & -0.070 & 0.296 & 0.233 & 0.326 & 0.175 & 0.340 & 0.232 & 0.230 & 0.179 & 0.220 \\
\hline Caregiver participation in St & lar Farmer & s' Mark & ets progra & nme & & & & & & & & \\
\hline No & $\mathrm{Re}$ & & $\mathrm{Re}$ & & $\mathrm{Re}$ & & $\mathrm{Re}$ & & $\mathrm{Re}$ & & Ref & \\
\hline Yes & 0.730 & 0.373 & 0.284 & 0.181 & $0.459^{*}$ & 0.199 & $0.487^{*}$ & 0.207 & $0.428^{\star *}$ & 0.140 & $0.365^{\star *}$ & 0.134 \\
\hline
\end{tabular}

F\&V, fruits and vegetables; GED, General Educational Development; Ref., referent category.

${ }^{\star} P<0.05,{ }^{\star \star} P<0.01,{ }^{\star \star *} P<0.001$.

was very easy or easy to prepare fruits (85\%) and vegetables (82\%) that children would eat, compared with $51 \%$ and $42 \%$ prior to the classes, respectively (all $P<0 \cdot 0001$ ). The scale for ease of fruit and vegetable preparation increased from $2 \cdot 4$ to $3 \cdot 1(P<0 \cdot 001)$.

Regression analyses demonstrated that findings remained significant when controlling for child and caregiver age and gender, caregiver education, market and caregiver participation in the adult-focused Stellar Farmers' Markets programme. Child age, child gender and caregiver participation in the Stellar Farmers' Markets programme were significantly associated with some outcomes. The number of classes attended by the child that year was not significantly associated with any outcome (Table 4).

\section{Health Bucks and programme participation}

Seventy-three per cent of respondents reported that their children usually or always used their Health Bucks coupon to purchase the fruit or vegetable prepared in class that day. When asked how likely they would be to attend Farmers' Markets for Kids classes if there were no Health Bucks incentive, $67 \%$ of respondents said they were very 
likely or likely to attend, $25 \%$ responded as somewhat or very unlikely to attend and $8 \%$ were unsure. Most respondents reported shopping at farmers' markets once per week (56\%) or more (27\%). Almost all respondents (99\%) reported purchasing more fruits and vegetables since participating in Farmers' Markets for Kids and 95\% had prepared the programme's recipes at home (data not shown).

\section{Sensitivity analyses}

Eighty-five per cent of respondents had participated in Stellar Farmers' Markets previously. Overall, respondents who had participated in Stellar Farmers' Markets reported more positive behaviours and attitudes related to fruits and vegetables both before and after participating in Farmers' Markets for Kids as compared with those who had not participated in Stellar Farmers' Markets, and most of these differences were statistically significant. However, there were no significant differences related to the improvements seen between child and caregiver behaviours and attitudes before participating in Farmers' Markets for Kids as compared with current behaviours and attitudes between these two groups of respondents; in other words, the differences between outcomes of interest before participating in Farmers' Markets for Kids and current outcomes were equivalent (data not shown).

When comparing respondents who were likely to attend Famers' Markets for Kids without the Health Bucks incentive ( $n$ 141) and those who were unlikely to do so ( $n$ 53), we found no significant differences in outcomes of interest or in respondent demographics, such as education level or gender, or by market.

\section{Discussion}

Our findings suggest that Farmers' Markets for Kids was effective in improving behaviours and attitudes related to fruit and vegetable consumption among participating children. Specifically, caregivers reported that since participating in Farmers' Markets for Kids, their children consumed a greater quantity and variety of produce, helped with food preparation more frequently and were more willing to try new fruits and vegetables. In addition, caregivers felt it was easier to prepare produce for their children following participation in the programme. Based on responses to retrospective pre-test/post-test questions, all of these improvements were statistically significant.

While the present evaluation was not designed to determine the extent to which various elements of the programme contributed to positive changes in participants, a number of the components used in the Farmers' Markets for Kids model have been linked to positive outcomes in other studies. First, Farmers' Markets for Kids provided education for both the caregiver and the child. A review of dietary interventions among overweight children suggested that tailoring programming for both children and parents may be more effective than focusing on only the parent or the child ${ }^{(23)}$. Second, Farmers' Markets for Kids offers sensory-based exposure to fruits and vegetables along with opportunities to taste these items in simple recipes. Our finding that children were more willing to try new fruits and vegetables after Farmers' Markets for Kids participation is consistent with studies showing that children were more likely to try new fruits and vegetables following interventions which focused on exposure to new produce varieties ${ }^{(24)}$ or provided sensory experiences with fruits and vegetables ${ }^{(25,26)}$. Third, Farmers' Markets for Kids addresses access to fruits and vegetables by conducting classes in the farmers' market environment, where fresh produce is abundant, and through provision of a \$US 2 Health Bucks coupon to both the caregiver and child. Providing this coupon increases families' financial resources for fresh produce and allows them to immediately purchase produce and act upon the information learned in the class. A number of studies have found that providing vouchers for farmers' markets produce to women enrolled in WIC was associated with significant increases in produce consumption, including an evaluation of a farmers' market-based multicomponent programme for WIC beneficiaries that found pairing nutrition education with coupons resulted in a larger increase in fruit and vegetable intake among programme participants than providing either intervention individually ${ }^{(10)}$. Additionally, farmers' markets may offer unique health-promoting qualities ${ }^{(9)}$.

Surprisingly, no significant dose-response relationship was found between the number of Farmers' Markets for Kids classes attended and improvements in outcomes of interest. This finding may reflect limitations of the evaluation design. For example, the survey measures may have been insufficiently sensitive and, thus, unable to detect a dose-response effect; or the sample may have been too small to yield significant findings when parsed by the number of classes attended. It bears noting that our finding of a reported increase of 1.8 cups of fruits and vegetables daily was larger than increases typically reported from other nutrition education programmes. For example, Knai et al. reviewed interventions to increase children's produce consumption and found increases ranging from 0.30 to 0.99 servings (i.e. 0.15 to 0.50 cups) ${ }^{(27)}$, and even for studies of multicomponent programmes for adults, increases of 1.4 servings/d are among the highest reported ${ }^{(28)}$. Given these findings, further research is required to confirm the magnitude of the increases found in the current evaluation. There is a possibility that the retrospective pre-test/post-test design inflated changes seen from pre to post due to altered post-test responses ${ }^{(29)}$; however, some researchers have concluded that the retrospective pre-test/post-test design is more accurate and efficient than a pre-test/post-test survey design for purposes of programme evaluation. 
Notably, Swindle et al. considered the relative benefits of these two study designs for evaluating a nutrition education programme and concluded that there were no substantial differences in the responses produced by traditional pre-test/post-test surveys $v$. retrospective pre-test/post-test surveys. The authors suggested that because the retrospective pre-test/post-test design offers logistical and other benefits, this approach is the more efficient method to meet the needs of programme evaluation ${ }^{(18)}$.

The current evaluation has additional limitations. Data were self-reported and collected through a cross-sectional survey. There was no control group or follow-up with participants to examine the long-term impact of the programme. Respondents were not randomly selected and our study sample was not representative of low-income populations nationally, limiting the generalizability of our findings. Additionally, the retrospective pre-test questions may have introduced biases related to recall and/or social desirability ${ }^{(18)}$. Future evaluations should include innovative strategies to follow up and track programme participants in longitudinal analyses, including examining behaviours and attitudes following the conclusion of the programme to determine whether improvements are sustained over time. Evaluations should also focus on understanding the relative contributions of the various elements of this model to its success. In particular, the role of providing vouchers for produce to children should be explored, as this element marks a key difference between Farmers' Markets for Kids and other child-focused nutrition initiatives.

Strengths of the Farmers' Markets for Kids programme include use of a multicomponent model that not only provides caregivers and children with knowledge about the importance of nutrition, local produce varieties and easy, affordable ways to prepare them, but also operates within the farmers' market environment. This environment offers participants immediate opportunities to act on newly acquired information and support for positive choices through Health Bucks coupons. The current evaluation responds to calls for more research and evaluation of farmers' market-based nutrition programmes and contributes to the body of evidence for such efforts. Our findings suggest that Farmers' Markets for Kids is a successful approach for increasing produce consumption among participating children and improving related attitudes among children and caregivers, and provides support for future efforts to undertake more rigorous evaluations of such programmes.

\section{Acknowledgements}

Acknowledgements: The authors would like to thank Alyson Abrami, Elizabeth Solomon, Tamar Adjoian, Shannon Farley and Michael Johns for their assistance with this project. Financial support: This work was supported by a grant from the Doris Duke Charitable Foundation and by the NYC Department of Health and Mental Hygiene. The Doris Duke Charitable Foundation had no role in the design, analysis or writing of this article. Conflict of interest: None. Authorship: R.D. led the study design, data analysis, interpretation of results, and the writing and editing process. E.B. led the implementation of the programme and A.O. led implementation of the evaluation; both contributed to evaluation planning, analysis and interpretation of the data, and writing and editing of the manuscript. R.S. contributed to data interpretation, and writing and editing the manuscript. Ethics of buman subject participation: The evaluation was reviewed by the NYC Department of Health and Mental Hygiene Institutional Review Board and was exempt from review as a public health programme evaluation.

\section{References}

1. Centers for Disease Control and Prevention (2011) Strategies to Prevent Obesity and Other Chronic Diseases: The CDC Guide to Strategies to Increase the Consumption of Fruits and Vegetables. Atlanta, GA: US Department of Health and Human Services; available at http://www.cdc.gov/obesity/ downloads/fandv_2011_web_tag508.pdf

2. US Department of Agriculture \& US Department of Health and Human Services (2010) Dietary Guidelines for Americans, 2010, 7th ed. Washington, DC: US Government Printing Office; available at http://www.cnpp.usda.gov/ sites/default/files/dietary_guidelines_for_americans/Policy Doc.pdf

3. Drenowski A \& Rehm CD (2015) Socioeconomic gradient in consumption of whole fruit and $100 \%$ fruit juice among US children and adults. Nutr J 14, 3 .

4. Darmon N \& Drewnowski A (2008) Does social class predict diet quality? Am J Clin Nutr 87, 1107-1117.

5. New York City Department of Health and Mental Hygiene (2009) 2009 Child Community Health Survey. https://a816healthpsi.nyc.gov/SASStoredProcess/guest?_PROGRAM=\% 2FEpiQuery\%2FChild\%2Fchildindex (accessed August 2015).

6. Harries C, Koprak J, Young C et al. (2014) Moving from policy to implementation: a methodology and lessons learned to determine eligibility for Healthy Food Financing Projects. J Public Health Manag Pract 20, 498-505.

7. Young CR, Aquilante JL, Solomon S et al. (2013) Improving fruit and vegetable consumption among low-income customers at farmers markets: Philly Food Bucks, Philadelphia, Pennsylvania, 2011. Prev Chronic Dis 10, 120356.

8. Herman DR, Harrison GG, Abdelmonem AA et al. (2008) Effect of a targeted subsidy on intake of fruits and vegetables among low-income women in the Special Supplemental Nutrition Program for Women, Infants and Children. Am J Public Health 98, 98-105.

9. Evans AE, Jennings R, Smiley AW et al. (2012) Introduction of farm stands in low-income communities increases fruit and vegetable among community residents. Health Place 18, $1137-1143$.

10. Anderson JV, Bybee DI, Brown RM et al. (2001) 5 a day fruit and vegetable intervention improves consumption in a lowincome population. J Am Diet Assoc 101, 195-202.

11. Anliker JA, Winne M \& Drake LT (1992) An evaluation of the Connecticut farmers' market coupon program. J Nutr Educ 24, 185-191. 
12. Dannefer R, Abrami A, Rapoport R et al. (2015) A mixed methods evaluation of a SNAP-Ed farmers' market-based nutrition education program. J Nutr Educ Behav 47, 516-525.

13. Sacks R, Yi SS \& Nonas C (2015) Increasing access to fruits and vegetables: perspectives from the New York City experience. Am J Public Health 105, e29-e37.

14. Toprani A \& Hadler JL (2013) Selecting and applying a standard area-based socioeconomic status measure for public health data: analysis for New York City. New York City Department of Health and Mental Hygiene: Epi Research Report, May 2013. http://www.nyc.gov/html/doh/ downloads/pdf/epi/epiresearch-SES-measure.pdf (accessed September 2015).

15. US Census Bureau (2009-2013) 5-Year American Community Survey. http://factfinder.census.gov/faces/ tableservices/jsf/pages/productview.xhtml?src=bkmkhttps:// www.census.gov/easystats/ (accessed August 2015).

16. Williams PA, Cates SC, Blitstein JL et al. (2014) Nutritioneducation program improves preschoolers' at-home diet: a group randomized trial. J Acad Nutr Diet 114, 1001-1008.

17. Hill LG \& Betz DL (2005) Revisiting the retrospective pretest. Am J Eval 26, 501-517.

18. Swindle S, Baker SS \& Auld GW (2007) Operation Frontline: assessment of longer-term curriculum effectiveness, evaluation strategies, and follow-up methods. J Nutr Educ Behav 39, 205-213.

19. Lohse B (2007) Nutrition educators ask hard questions. J Nutr Educ Behav 39, 245-246.

20. Rohs FR, Langone CA \& Coleman RK (2001) Response shift bias: a problem in evaluating nutrition training using selfreport measures. J Nutr Educ Behav 33, 165-170.

21. Townsend MS, Davidson C, Leavens L et al. (2006) Administering the UCCE Food Behavior Checklist with Supplemental Questions: Instruction Guide. California: University of California Cooperative Extension; available at
http://townsendlab.ucdavis.edu/PDF_files/UCCE/UCCE_FBC_ InstructGuide.pdf

22. US Department of Agriculture, Food and Nutrition Service, Office of Research and Analysis (2012) SNAP Education and Evaluation Case Study Report: New York State Department of Health's Eat Well Play Hard in Child Care Settings Program. Alexandria, VA: US Government Printing Office; available at http://www.fns.usda.gov/sites/default/ files/SNAP-EdWave1EatWell_VolI_0.pdf

23. Bourke M, Whittaker $\mathrm{P}^{-}$\& Verma A (2014) Are dietary interventions effective at increasing fruit and vegetable consumption among overweight children? A systematic review. I Epidemiol Community Health 68, 485-490.

24. Schindler JM, Corbett D \& Forestell A (2013) Assessing the effect of food exposure on children's identification and acceptance of fruits and vegetables. Eat Behav 14, 53-56.

25. Reverdy C, Chesnel F, Schlich P et al. (2008) Effect of sensory education on willingness to taste novel food in children. Appetite 51, 156-165.

26. Dazeley P \& Houston-Price C (2015) Exposure to foods' non-taste sensory properties. A nursery intervention to increase children's willingness to try fruit and vegetables. Appetite 84, 1-6.

27. Knai C, Pomerleau J, Lock K et al. (2006) Getting children to eat more fruit and vegetables: a systematic review. Prev Med 42, 85-95.

28. Pomerleau J, Lock K, Knai C et al. (2005) Interventions designed to increase adult fruit and vegetable intake can be effective: a systematic review of the literature. J Nutr $\mathbf{1 3 5}$, $2486-2495$.

29. Nolte S, Elsworth GR, Sinclair AJ et al. (2012) The inclusion of 'then-test' questions in post-test questionnaires alters post-test responses: a randomized study bias in health program evaluation. Qual Life Res 3, 487-494. 